\title{
$\mathrm{PH} 103$
}

actualdad

\section{La declaración de geoparque mundial de la Unesco de Granada amplía expectativas para el desarrollo del territorio}

La provincia de Granada cuenta con un nuevo geoparque perteneciente a la Red Mundial de la Unesco desde el pasado año 2020. La singular y excepcional geología relacionada con la cuenca de GuadixBaza, su registro del Cuaternario, sus paisajes inalterados y su patrimonio geológico (paleontológico) de relevancia internacional (Geosites, Ley 42/2007 de Patrimonio Natural y Biodiversidad) han sido los argumentos científico-técnicos esenciales para la aprobación de esta candidatura. Un geoparque es ante todo una oportunidad territorial de apoyo al futuro para las gentes que habitan en escenarios naturales prístinos.

Juan José Manrique López | Grupo de Desarrollo Rural de Guadix

Alfonso Arribas Herrera, José Antonio Garrido García | Estación Paleontológica Valle del Río Fardes, Instituto Geológico y Minero de España, Consejo Superior de Investigaciones Científicas (CSIC)

URL de la contribución <http://www.iaph.es/revistaph/index.php/revistaph/article/view/4897>

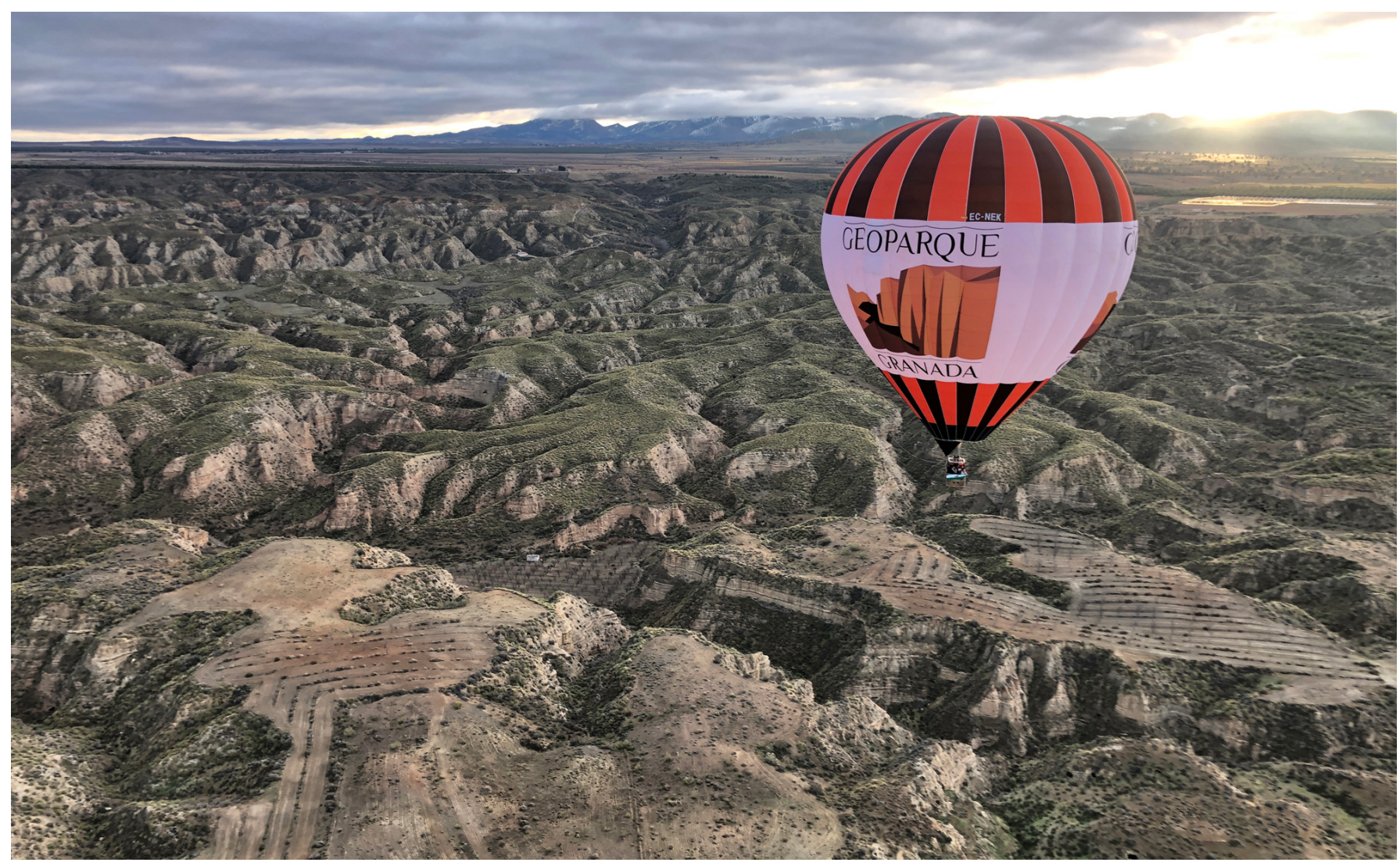

Vista aérea de parte de los badlands de la hoya de Guadix en el Geoparque de Granada. Se observan los barrancos orientales tributarios del río Fardes, los llanos (glacis) del este y los lejanos relieves de Sierra de Baza | foto Gloventosur S.L. 
Los geoparques mundiales de la Unesco son áreas geográficas únicas y unificadas donde los sitios y paisajes de importancia geológica internacional se gestionan con un concepto holístico de protección, educación y desarrollo sostenible. Un geoparque utiliza su patrimonio geológico, en relación con todos los demás aspectos del patrimonio natural y cultural del territorio, para mejorar la conciencia y la comprensión de los problemas clave a los que se enfrenta la sociedad, como el uso sostenible de los recursos, la mitigación de los efectos del cambio climático y la reducción de riesgos relacionados con desastres naturales. Al crear conciencia sobre la importancia del patrimonio geológico del área, los geoparques mundiales de la Unesco brindan a la población local un sentido de orgullo por su territorio y fortalecen su identidad con el mismo, y suponen la creación de empresas locales innovadoras. En la actualidad, hay 161 geoparques mundiales de la Unesco en 44 países.

Un geoparque de la red mundial de la Unesco, por tanto, es una oportunidad para la conservación patrimonial (patrimonio natural geológico y biológico como soporte del patrimonio cultural a lo largo del tiempo) y un apoyo sensible para la supervivencia humana en el medio rural en el siglo XXI.

Los antecedentes originarios para contar hoy en día con el primer geoparque de la provincia de Granada surge de la voluntad inicial, del GDR de Guadix y del Instituto Geológico y Minero de España, de poner en marcha una estrategia participativa de desarrollo sostenible en el territorio, otorgando especial importancia a la geología y a los elementos de la misma que forman parte del patrimonio natural, hace casi dos lustros. A este proyecto se sumó unos pocos años después el GDR de Altiplano de Granada y más recientemente distintas entidades públicas y privadas que han configurado el grupo promotor, entre ellas la Diputación Provincial de Granada, que ha liderado el proceso de presentación de la candidatura ante la Unesco.

El Geoparque de Granada, aprobado e incluido en la Red Mundial de la Unesco el pasado mes de julio de 2020, ocupa en su delimitación gran parte de la mitad noro- riental de la provincia de Granada (comarcas de Guadix, Baza, Huéscar y parte de Los Montes) y en él están representados al menos los últimos 250 millones de años de la historia geológica de nuestra Tierra, de los que los últimos 2,53 millones de años, el periodo Cuaternario, son los auténticos protagonistas del geoparque. En este periodo, dentro del territorio, quedó registrada una de las sucesiones estratigráficas más completas del Cuaternario continental del planeta, con algunos de los mejores y más completos yacimientos paleontológicos de macro vertebrados de toda Europa. Posteriormente los procesos geomorfológicos, con la ayuda de la tectónica, han generado los actuales paisajes.

Pero no se trata solo de geología espectacular, el geoparque es mucho más. La idea es que una geología singular y unos valiosos ecosistemas subdesérticos, con comunidades vegetales, fauna y flora únicos o extremadamente raros en Europa, especialmente bellos, sean la matriz o algunos de los elementos tractores que permitan sacar del olvido, en unos casos, y aumentar la visibilidad, en otros, a los restantes tipos de patrimonio presentes en el territorio (etnográfico, histórico, y arqueológico extraordinarios, con algunos de los testimonios de presencia humana más antiguos en Europa y un amplio repertorio de yacimientos protohistóricos e históricos, incluyendo conjuntos megalíticos y poblados fortificados calcolíticos y argáricos, núcleos urbanos ibéricos y romanos, además de fortificaciones y cuevas

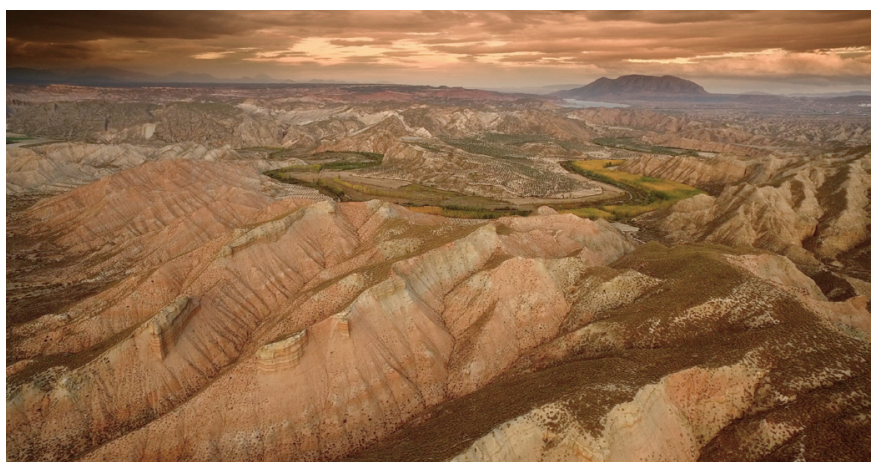

Vista aérea de parte del sector occidental (Tierra de badlands) del Geoparque de Granada. En vuelo hacia levante se observa en primer plano parte de Los Coloraos, a continuación, algunos de los meandros del Guadiana Menor y tras ellos el pantano del Negratín y el Cerro Jabalcón, que da paso al sector oriental del geoparque | foto Alberto Tauste 
medievales). Esta integración genera la posibilidad de poner en marcha nuevas iniciativas de innovación social, relacionadas con la custodia del territorio o vinculadas al propio paisaje, y empresariales fomentando actividades innovadoras vinculadas a la gestión e interpretación patrimonial y cultural, a la educación ambiental, al ecoturismo, al fomento de la agroecología y la artesanía, y a la valorización de las producciones locales, entre otras.

No obstante, un geoparque no es nada sin las personas que lo habitan, sin su participación activa. Un geoparque ha de ser útil y aportar valor a los habitantes del territorio, útil de forma objetiva, sostenible y conservativa de los recursos naturales. Por ello es importantísima la implicación de la sociedad local, su conocimiento de lo que supone un geoparque y la estrategia de desarrollo sostenible que lleva aparejada, siendo esencial su aceptación y apoyo a una herramienta útil para sus vidas. Una herramienta útil, entre otras necesarias, para frenar el grave problema de despoblación que atesora esta tierra.

A efectos prácticos un geoparque no tiene asociadas figuras restrictivas de usos del territorio. Es más la suma de voluntades, que la imposición de normas o criterios. Por ello es singular este geoparque en su integridad, pero lo es aún más su porción "pura" de territorio natural, más de 1.400 kilómetros cuadrados de un paisaje salvaje semidesértico constituido por millares de barrancos, crestas, farallones y mesetas, sin apenas impacto humano, que ha llegado casi intacto hasta nuestros días. Un semidesierto maravilloso conservado por los usos y costumbres aplicados a estas tierras a lo largo de siglos. Duro era habitar aquellas tierras, por falta de abundancia de recursos útiles para grandes poblamientos humanos (nos referimos a los badlands) y duro sigue siendo en el siglo XXI. Por ello, para una correcta conservación de aquellos espectaculares paisajes lo que se ha de hacer es no interferir en ellos y dejar que la Tierra y sus agentes naturales sigan su curso. Esta es la más adecuada fórmula de conservación y protección (geoconservación genérica pasiva) en este caso.

Con esta dinámica, la potencia de estos paisajes es tal (junto con su patrimonio geológico, yacimientos paleon-

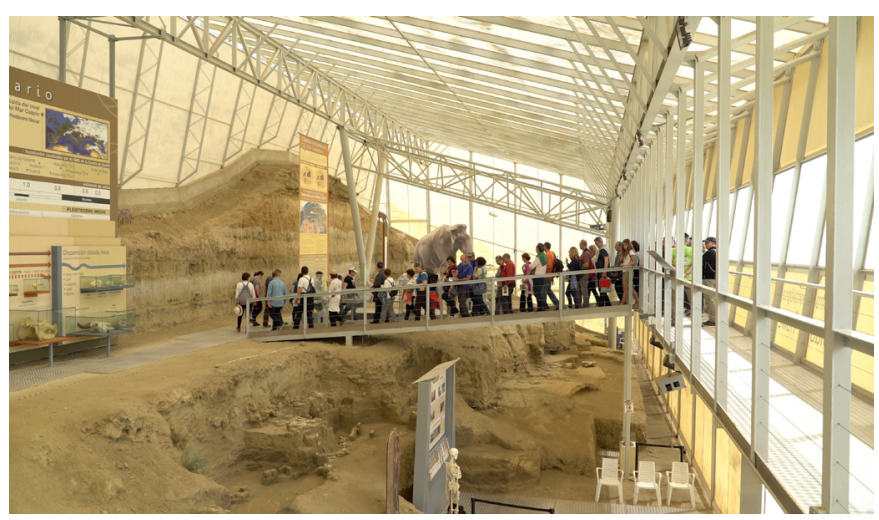

Aspecto de la Estación Paleontológica Valle del Río Fardes del IGME (yacimiento paleontológico Fonelas P-1) durante la visita de uno de los grupos participantes en el Geolodía18 (Sociedad Geológica de España) Granada. Esta actividad en 2018 consistió en la divulgación de las historias geológicas de Fonelas P-1 y del teatro romano de Guadix | foto Alberto Tauste

tológicos y arqueológicos, etnografía, modo de vida ancestral y fauna y flora actuales) que se convierte en un recurso cultural en sí mismo y como tal en un recurso turístico de interior de primera magnitud, único en el continente europeo. Esta es la escala de las cosas y también la potencia económica, cuyos desarrollos han de ser sostenibles con lo natural -incluido lo humano-, y suponer a largo plazo un verdadero apoyo a las gentes del terruño. Todo ello, si se gestiona de forma correcta en el tiempo, se aúnan voluntades y se construye una visión territorial compartida, configura un escenario social en el cual la conservación y la puesta en valor de todos los tipos de patrimonio son algo indiscutible por necesarios. Enormes son los retos, pero ese es uno de los fines y otro de los sueños. 